\title{
The use of minimally invasive videoscopic technique in large vessel and cardiac surgery. Does the potentially increased difficulty bring benefits to the patient?
}

\author{
Maciej Rachwalik ${ }^{1}$, Tomasz Płonek ${ }^{1}$, Wojciech Kustrzycki ${ }^{1}$, Przemysław Szyber², Stanisław Pawłowski², Waldemar Goździk ${ }^{3}$ \\ 1Department and Clinic of Cardiac Surgery, Medical University of Wrocław, Poland \\ 2Department and Clinic of Vascular, General and Transplantation Surgery, Medical University of Wrocław, Poland \\ ${ }^{3}$ Department of Anaesthesiology and Intensive Therapy, Medical University of Wrocław, Poland
}

Videosurgery Miniinv 2013; 8 (1): 86-89

DOI: $10.5114 /$ wiitm.2011.31596

\begin{abstract}
We present the clinical case of a 63-year-old patient who underwent in the Department of Cardiac Surgery implantation of an aorto-bifemoral graft prosthesis and coronary artery bypass revascularization with application of less invasive off-pump technique. Graft selection (arterial grafts, venous grafts) is very important during qualification for coronary artery bypass revascularization. Minimally invasive saphenous vein harvesting was performed during the presented case. The endoscopic technique of vein harvesting is a relatively rarely applied technique during myocardial revascularization surgery. The concept of minimally invasive videoscopic technique is presented. There is a discussion on why the team decided to prolong duration of the case consisting of two major operations performed simultaneously. Minimally invasive videoscopic technique may have a significant positive impact on postoperative outcome in a selected group of patients.
\end{abstract}

Key words: endoscopic vein harvesting, coronary artery bypass grafting, " $\gamma$ " prosthesis, cardiac surgery, vascular surgery.

\section{Case report}

We present a patient with coronary artery disease and peripheral atherosclerosis, who underwent surgery combining coronary artery revascularization and aorto-bifemoral graft prosthesis implantation. The 63-year-old patient initially referred for treatment to the vascular surgery department. On the day of planned surgery, after the introduction of general anesthesia, myocardial ischemic changes were observed in the form of deep ST segment denivelation in leads from the side wall. The consulting cardiologist recommended that the surgery be postponed and the patient referred for angiography. Two vessel coronary artery disease in the anterior descending artery (LAD) and circumflex artery (Cx) was detected on the basis of coronary angiography (Photo 1 ). There was a failed attempt to perform percutaneous coronary intervention $(\mathrm{PCl})$ with drug-eluting stent (DES) implantation to the $C x$.

After consultation within the Heart Team [1] that included a heart surgeon, cardiologist, vascular surgeon, and anesthesiologist, the patient was scheduled for a combined cardiac and vascular procedure. After standard general anesthesia [2], median sternotomy was performed first and the left internal 
mammary artery (LIMA) and vein were harvested in endoscopic fashion. Less invasive cardiac revascularization was performed, without cardiopulmonary bypass, using the Octopus system [3]. Two anastomoses were done: LIMA to the LAD and venous bypass to the $C x$. The chest was temporarily closed after adequate hemostasis. A second team consisting of vascular surgeons performed $Y$ prosthesis implantation in a conventional manner [4]. After this part of the treatment the chest was closed in a typical manner. Surgery was finished at 3 PM $6 \mathrm{~h}$ after its beginning. The postoperative course was uneventful. The patient, hemodynamically stable, was extubated on day one. After 3 days of stay in intensive care the patient was transferred to the cardiac ward and then discharged to the local hospital for further rehabilitation.

\section{Discussion}

The combination of two relatively serious operations, on the same day, is a big burden for the patient, especially for the circulatory system in the perioperative and postoperative period. There are also a number of important issues related to the postoperative reperfusion, wound healing and postoperative pain. In the absence of clear guidelines, an important decision seems to be the choice of strategy of operation and determination in which manner to perform revascularization before vascular surgery. The European Society of Cardiology (ESC) guidelines give recommendations for carotid revascularization procedures combined with coronary revascularization, but do not give precise guidelines on peripheral arterial disease [1]. We recognized that the use of cardiopulmonary bypass would have a negative impact on the critically ischemic lower leg arteries. Minimally invasive direct coronary artery bypass surgery (MIDCAB) using video assistance would be another option; however, this technique makes it possible to revascularize the anterior wall [5]. The patient's problem was related mainly to the Cx artery, previously unsuccessfully treated with percutaneous technique. In the need for regular access by the median sternotomy the problematic issue of an additional vascular conduit emerged.

There were three options to consider: internal thoracic arteries, radial arteries and saphenous veins. Amputation of legs in such an advanced peripheral vascular disease and thus the need to move around on crutches with potential weakening of the strength of the chest were taken into account; thus sternotomy and harvesting of both thoracic arteries would be unadvisable.

We decided against harvesting the radial artery due to potential weakness of the hands and the threat of severe atherosclerosis answering atherosclerosis in the lower extremities. The decision to collect the saphenous vein from chronically ischemic lower limbs was also burdened with a relatively high risk associated with wound healing. A conventional long incision of the leg is associated with a higher infection rate, as well as poorer and longer healing of wounds. A potential solution was minimally invasive technique [6]. The less ischemic leg, with less marked trophic changes, was selected for endoscopic surgery. There are few publications on the use of endoscopic techniques to harvest the saphenous vein in vascular surgery, in contrast to the fairly frequent application in cardiac surgery [7].

Endoscopic technique has been evaluated to improve wound healing after harvesting of the vein with a video scope in vascular surgery [8]. We assumed that a right transverse incision with a width of $3 \mathrm{~cm}$ (Photo 2) on the ischemic limb would heal faster than a conventional incision. We found no data on wound healing after endoscopic harvesting for cardiac surgery from limbs which had vascular surgery. This may be further confirmation of an interesting trend regarding the distribution of frequencies of endoscopic

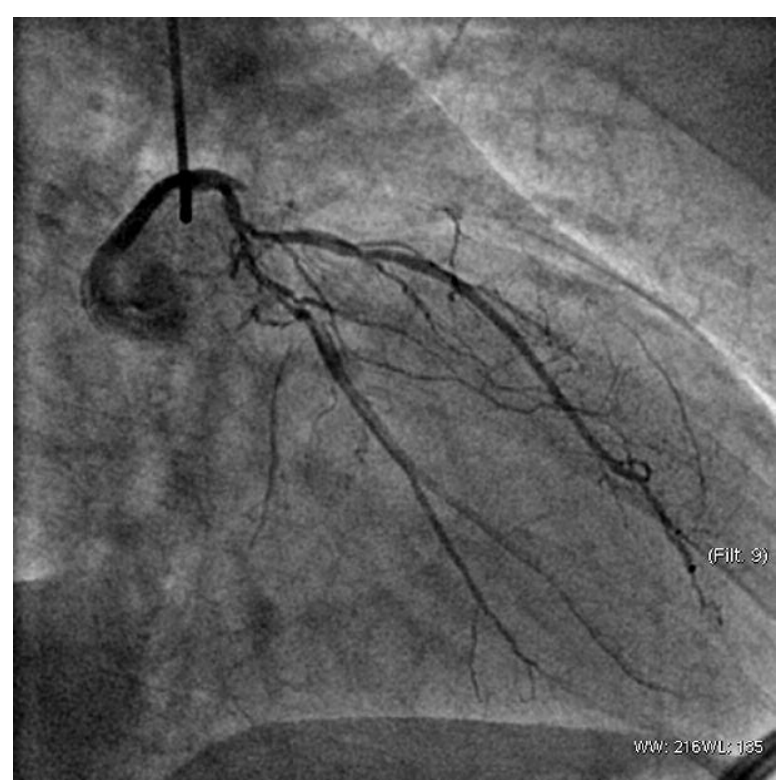

Photo 1. Coronary angiography of the patient 


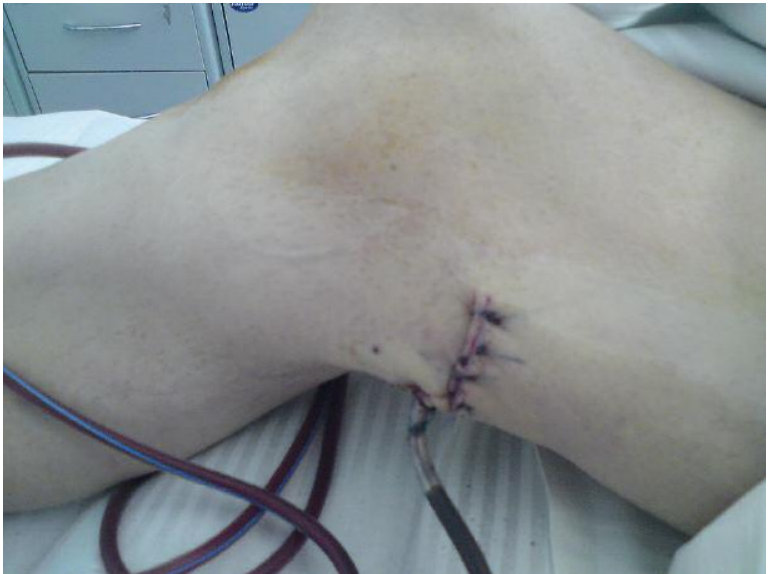

Photo 2. Incision on the right leg

harvesting in Europe and the US [9]. In EU countries, this method is not very widely used. The situation is different in the US, where $90 \%$ of conduits are harvested in this way. However, in the US specially trained paramedics who are not involved in heart operations are responsible for venous conduits for coronary artery bypass grafting (CABG).

Minimally invasive techniques are areas that require proper training and a high repeatability of results [10]. The nature of training in cardiac surgery impacts on the interest in harvesting veins in endoscopic fashion. In European countries veins are harvested mainly by junior doctors at the beginning of their training or before the official start of their training. They mistakenly consider it as a transitional stage in their training and are not interested in mastering their skills in these methods. It seems that the current funding of minimally invasive harvesting, especially by disposable sets, does not promote this technique. The quality of bridges is critical for longterm benefits of CABG [11]. No major histological differences between the conduits collected traditionally or in endoscopic fashion have been evaluated in randomized studies [12].

There are no randomized studies showing worse patency of grafts taken by videoscopic technique $[13,14]$. Endoscopic harvesting involves manipulation in an iatrogenically created tunnel whose walls can be either filled by gas supplied by a trocar or supported by a "Freiburg" endoscopic artery retractor with a camera. This second video surgical technique seems to be more challenging, especially when we clip a lot of side branches on the vein. In this technique it is important to maintain adequate endo- scopic hemostasis. Hemostasis has a threefold significance for the patient: it facilitates efficient harvesting and helps to avoid uncontrolled movements that can damage the vein; it facilitates the adhesion and bonding of the iatrogenic tunnel after the removal of instruments from tissue; and proper hemostasis reduces the risk of wound infection. Disposable sets are relatively expensive, which is not a factor prohibiting their regular use. Reusable sets seem to be a more common form of tools in endoscopic vein harvesting. Here the surgeon should pay attention to a few aspects of endoscopic harvesting. One of them is the need for appropriate tunnel elevation at which the vein is taken as the ceiling to move the hooks, scissors, and clip device. Establishment of vascular clips to the side branches and perforators seems to be quite complex, especially with sets without obliteration systems.

Taking into account the fact that after the harvesting of veins we were planning two large operations, one might abandon an attempt to prolong the treatment time by videoscopic technique. Does it minimize the risk of treatment? Adequate understanding of the goals of surgery by the vascular and cardiac surgeons favors collection of a good quality conduit. In our opinion, minimally invasive techniques could prolong the operation; however, this translates into optimizing the quality of surgery.

\section{References}

1. Joint ESC/EACTS guidelines on myocardial revascularistion/ www.escardio.org/guidelines

2. Rachwalik M, Lysenko L, Kustrzycki W. Comparison of spirometry in patients after on pump and off pump coronary artery bypass grafting. Anesth Int Therapy 2006; 38: 4-7.

3. Scott NA, Knight JL, Bidstrup BP. Systematic review of beating heart surgery with the Octopus Tissue Stabilizer. Eur J Cardiothorac Surg 2002; 21: 804-17.

4. Pupka A, Janczak D, Szyber PP. The heparin-bonded ePTFE grafts in revascularisation of the lower limbs. Polim Med 2010; 40: 9-14.

5. Reddy RC. Minimally invasive direct coronary artery bypass: technical considerations. Semin Thorac Cardiovasc Surg 2011; 23: $216-9$.

6. Nickum CW. Endoscopic vessel harvesting in coronary artery bypass graft surgery. JAAPA 2005; 18: 40, 42, 44, 51-3.

7. Gazoni LM, Carty R, Skinner J. Endoscopic versus open saphenous vein harvest for femoral to below the knee arterial bypass using saphenous vein graft. J Vasc Surg 2006; 44: 282-7.

8. Julliard W, Katzen J, Nabozny M. Long-term results of endoscopic versus open saphenous vein harvest for lower extremity bypass. Ann Vasc Surg 2011; 25: 101-7. 
9. STS adult cardiac surgery database. Chicago: Society of Thoracic Surgeons, 2008; 22, 2009.

10. Kiani S, Poston R. Is endoscopic harvesting bad for saphenous vein graft patency in coronary surgery? Curr Opin Cardiol 2011; 26: 518-22.

11. Kiani S, Desai PH, Thirumvalavan N. Endoscopic venous harvesting by inexperienced operators compromises venous graft remodeling. Ann Thorac Surg 2012; 93: 11-8.

12. Kiaii B, Moon BC, Massel D, Langlois YJ. A prospective randomized trial of endoscopic versus conventional harvesting of the saphenous vein in coronary artery bypass surgery. Thorac Cardiovasc Surg 2002; 123: 204-12.

13. Lopes RD, Hafley GE, Allen KB, et al. Endoscopic versus open veingraft harvesting in coronary artery bypass surgery. N Engl I Med 2009; 361: 235-44.

14. Allen K. Endoscopic vascular harvest in coronary artery bypass grafting surgery: a consensus statement of the International Society of Minimally Invasive Cardiothoracic surgery (ISMICS) 2005. Innovations 2005; 1: 1-60.

Received: 22.04.2012, revised: 28.05.2012, accepted: 7.07.2012 